\title{
AGORA $\begin{array}{lr}\text { G } & \text { G } \\ O & O \\ \text { R } & \text { R } \\ \text { AGORA }\end{array}$
}

AGORA is a lighter channel of communication between readers and contributors; it aims to stimulate discussion and debate, particularly by presenting new ideas and by suggesting alternative interpretations to the more formal research papers published in WeB ECOlOGY and elsewhere. A lighter prose is encouraged and no summary is required. Formal research papers, however short, will not be considered.

\section{"Towards establishing ecology as a science instead of an art": the work of John T. Curtis on the plant community continuum}

\author{
Malcolm Nicolson (wellmn@arts.gla.ac.uk), Wellcome Unit for the History of Medicine, 5 University \\ Gardens, Univ. of Glasgow, Glasgow, U.K. G12 8QQ.
}

\begin{abstract}
Until the 1950s, American plant ecology was dominated by the community-unit theory - that plants grow together in definite communities which constitute the proper subject matter for ecological research. Only H. A. Gleason proposed the alternative "individualistic hypothesis". In the 1950s the nature of the plant community was re-examined in a number of field studies. John Curtis led a re-assessment of ecological theory. This paper provides a historical analysis of aspects of his work.

Born in 1913, Curtis did his doctorate at the Univ. of Wisconsin, under Benjamin Duggar, receiving a fine training in physiological research. In 1941, he made a career shift toward community ecology. Dubious of the validity of the concept of the plant community, Curtis began an intensive investigation of the vegetation of Wisconsin. American ecology was in an insecure position, isolated from the mainstream of biological science. Curtis's ambition was reform - to establish ecology as "a science rather than an art". The improvement of research methodology was a major concern.

Curtis and his colleagues found that the best way to arrange the data from their study stands was into a sequence of continuous variation, each dominant gradually peaking in frequency along a continuum. There were no distinct "associations" of species. By the 1970s, the continuum, which Curtis presented as a vindication of Gleason, was accepted as a generally valid description of mature vegetation.
\end{abstract}

Up until the 1940s, plant ecology in America was dominated by the community-unit theory (Whittaker 1962, 1975). This is the concept that plants grow together in definite, recognisable, ordered, essentially repeating communities and that these natural kinds of vegetation constitute the proper subject matter for ecological study - in the same way as the plant species provides the proper object of study for taxonomic botanists (Nicolson 1984, 1989). The units were defined by a prominent American ecologist, George Nicholls, thus: "The association may be described as a vegetation-unit characterised by its essentially constant physiognomy and by its essentially constant floristic composition (Nichols 1923)".

The leading theorist of the community-unit theory in America was Clements (1916, Hagen 1992). But the community-unit theory was widely accepted throughout 
American ecology, even by ecologists who, like Nichols, did not wholly accept Clements's views. Before 1945, only one American botanist expressed dissent from the community-unit theory - Henry Allan Gleason, protagonist for the alternative individualistic hypothesis (Gleason 1926, McIntosh 1975, Nicolson 1990).

After the War, however, this unanimity as to the fundamental nature of vegetation began to break down. A number of younger American ecologists expressed dissatisfaction with the state of ecological science and called for a cautious re-examination of the individualistic hypothesis (e.g. Cain 1947, Egler 1947, Mason 1947). In the 1950s, the nature of the plant community was investigated in a series of major field studies (Whittaker 1951, 1953, Curtis 1959a). One of the leaders of this re-assessment of ecological theory was John Curtis of the Univ. of Wisconsin. This paper provides a brief analysis of aspects of Curtis's work, and its reception by his colleagues.

American ecology in the 1940s and 1950s was in a difficult position (Odum 1977). It lacked prestige and prominence within the scientific community. In 1948, the editor of Ecology complained that, "people ... constantly question the right of ecology to be considered a science" (Lawrence 1948). Recruitment to the specialty was low and advancement for established ecologists was problematic. Ecology was suffering partly because it had not managed to associate itself with recent exciting developments in other areas of biology (Young 1954). The Carnegie Institution, which had been a major source of funds for ecological research in the first decades of the century (McIntosh 1983), was now more interested in funding population genetics (Hagen 1992). The Rockefeller Foundation was funding biological research but it was directing its monies to molecular biology, population genetics, and so on (Beadle 1967, Abir-Am 1982). The 1940s was also the era of the New Darwinian Synthesis, whose architects drew their support widely from throughout biology but who had not taken much notice of ecology. The problem for plant ecology was two-fold. Its subject matter was not encompassed within the New Synthesis and its principal theoretician, Clements, was an avowed Neo-Lamarckian, not a Darwinian at all (Tobey 1981). As Provine (1978) has noted, "By 1940 any evolutionist not a Neo-Darwinian was clearly out of step with the times".

In the period immediately after the Second World War, Clementsian ecology in general and the community-unit theory in particular were often criticised from a Darwinian perspective. For example, in 1947, Herbert Mason argued that plant communities were best thought of as assemblages of inter-breeding populations, a perspective he derived explicitly from evolutionary population genetics. There were therefore, in his view, no integrative processes working above the level of the population: "The organic functions of the population, then, are solely the functions of population genetics and result from the reproductive and genetic activity within the population. ... Furthermore, there are no organic functions that operate between genetically unrelated populations ... A community made up of such populations has neither organic nor functional unity but is an aggregation of independently operating populations of interbreeding individuals (Mason 1947)".

Therefore, Mason concluded: "Floristic evolution is activated by the interplay between environmental conditions and genetic and physiological phenomena that ... select those genetic races within the species population are preadapted to the new conditions. The production and selection of the genetic races must be construed as steps in the evolutionary process known as natural selection. (Mason 1947)".

It was essential, in Mason's view, if ecology was to be made harmonious with evolutionary population genetics and its related disciplines that the community-unit theory be abandoned.

In 1947, Mason, Cain and Egler all urged a re-assessment of the individualistic hypothesis. Gleason's emphasis on explanation at the level of individual plant species seemed to allow the possibility of a rapprochement between vegetation science and the Neo-Darwinian research programme. On the other hand, Clementsian plant ecology, being speculative, largely non-quantitative, isolated from the biological mainstream, provided a vivid image of what the new ecology could not afford to be. John Curtis and his colleagues in Wisconsin rose to the challenge of providing the discipline with an alternative exemplar, more harmonious with the character of high-status biology in the post-war period.

\section{John Curtis and the vegetation of Wisconsin}

Curtis was born in Waukeska, Wisconsin, in 1913 (for biographical details, see Nicolson 1984). While attending Carroll College, Waukeska, he became a protégé of Albert Fuller, Botanical Curator of the Milwaukee Museum, and published three short papers on natural history while still an undergraduate. Graduating A.B. in 1934, Curtis moved on to the Univ. of Wisconsin, Madison, where he graduated A.M. in 1935, and Ph.D. in 1938. He did his doctoral work under Professor Duggar. He also worked with Chancey Juday, on the bioassaying of productivity in lakes. In 1940, he was appointed Assistant Professor to the Botany Department in Madison. In 1942, he joined the Ecological Society of America.

Curtis's supervisor, Benjamin Duggar, was a plant physiologist of international renown (Walker 1958). For his doctorate, Curtis worked on the seed germination of native species of orchids, but, in essence, Duggar taught Curtis how to do good plant science. Duggar, moreover, sponsored a style of research in which laboratory experimentation was not an end in itself; he was also interested in environmental physiology and agronomy. Duggar was moreo- 
ver instrumental in setting up the first course in plant ecology to be taught at Madison. Thus, during his apprenticeship in Wisconsin, Curtis learned the very best techniques and principles of physiological research, in a context that made physiology relevant to the study of living plants in their natural habitat. Significantly the work Curtis did with Juday, a famous limnologist, involved the transposition of the measurement of biological productivity from the laboratory to the field (Curtis and Juday 1937). Curtis was not yet an ecologist, but he was very effectively preadapted to become one.

In 1941, Curtis made a definite shift in the emphasis of his research, towards community ecology. He applied to the Guggenheim Foundation for a year's support to investigate the phytosociology of the Lake Forest, an exercise in pure vegetation science. Curtis intended spending his Guggenheim Fellowship year with W. S. Cooper in Minnesota. His entry into ecology was, however, delayed. In 1942 the United States declared war and Curtis was made research director of the Emergency Rubber Project in Haiti. Experience of the exotic vegetation of the Caribbean exercised a formative effect, as Curtis struggled to apply to the tropical forest the ecological principles he had learned in temperate America (Curtis 1947).

Upon his return to Wisconsin, Curtis wrote to Cooper to say that he no longer intended to pursue his project on the Lake Forest. "I find myself with markedly different views concerning the general field of plant ecology than I had when I was last in Minneapolis. First hand study of the immensely complex group of tropical plant associations has ... undermined my faith in the possibilities of arriving at any clear-cut conclusion regarding the relationship of our own seemingly simple plant societies. The disillusionment has been so great that I now entertain serious doubts concerning the validity of the entire plant-association concept ... I am convinced that no meaningful definition can be forthcoming until we have far greater knowledge concerning the requirements and the behaviour of the individual species than we now possess (Curtis 1946)".

Curtis conceived a grand plan to provide the knowledge he saw as lacking. He persuaded the Wisconsin Alumni Research Foundation to fund a major, ten-year-long, investigation of the vegetation of the State of Wisconsin. The Foundation provided research support for Curtis and other faculty members and also financed several graduate students. In the ten-year period from 1946, ten Ph.Ds and nine M.S. degrees were awarded to graduate students associated with the project (Curtis 1958a). All worked on topics handpicked for them by Curtis; each piece of research playing its definite role in his overall plan. Grant Cottam, a graduate student until 1948, joined the faculty in 1949 and continued to work closely with Curtis. Several other members of the Botany Department, including Norman Fassett and Henry C. Greene, were also involved in particular aspects of Curtis's grand scheme. Curtis was a skilful and inspiring project director: "He was very much the leader and you wound up after you got an education under Curtis being a disciple ... The graduates were a closelyknit group. We all met together once a week for lunch and it was friendly half-social, half-business ... He was an excellent teacher and he spent hours and hours with the graduate students - each of them had a one-hour appointment every week. He kept their nose to the grindstone (Cottam 1978)".

At the 1951 meeting of the American Ecological Society in Minneapolis, a total of nine papers were presented by Curtis and his students (Anon. 1951). By this time Curtis had created a distinctive research school (for remarks on the characteristics of successful research schools, see Morrell 1972, Geison and Holmes 1993).

Curtis had come into ecology with a mission to reform the discipline, "to go far", as he put it, "toward establishing ecology as a science instead of an art" (Curtis 1958b). He desired a new ecology that was "scientific, with rigorous requirements based on quantitative data" (Curtis 1959b). Thus, one of his great concerns was the improvement of ecology's research methodology. A considerable advance was made in 1947, when Curtis and his colleague, Grant Cottam, successfully applied the surveyor's method of "random pairs" to the sampling of woodland vegetation (Cottam and Curtis 1949). This technique allowed quantitative data to be generated much more quickly than ever before: "We had methods where one man could go out and sample, say, four stands in a day and in the course of a summer collect data on a hundred or so stands. Because of this we had a lot more data to work with. Up to that time most of the papers had been written over a single stand or two or three stands. But Curtis immediately put his students to work gathering data on lots of stands (Cottam 1978)".

Cottam and Curtis also pioneered the use of punched cards and calculating machines for the storage and manipulation of vegetational data (Cottam and Curtis 1948).

The first of the graduate students Curtis put to work on the random pairs sampling method was Robert P. McIntosh. To McIntosh, the ease with which data could now be collected encouraged a freer, less theory-laden, approach to vegetation sampling: "You got lots of data ... The distinction ... was quite clear in our minds that against the older approach whereby you classified subjectively and then went in and sampled your pre-classified groups as representatives, put these together as descriptive of what you had already classified - this kind of approach allowed you to put things together come what may ... (McIntosh 1978)".

Using the quadrat method a sample of woodland might take a week or so to complete. Therefore each sample had to be carefully placed so as to be optimally useful. When more than one could be done in a day, the investment in each was less. Sample plots could be placed more speculatively, with less of a fixed idea in the investigator's mind as to what each was intended to display. 
Curtis had no developed system of classification to which to introduce his students. Indeed, he was sceptical of all the existing systems. Curtis and McIntosh were, thus, faced with a problem. How were they to organise into a publishable form the large amounts of data that the new sampling technique had enabled them to generate?

Over many months, in 1948 and 1949, McIntosh worked towards a solution: " $\ldots$ one of the first approaches we took was the mechanical strip method. It's just a big board with a little strip across the bottom and we cut long narrow white plastic strips and then marked quantities and then basically just lined them up and shuffled them back and fore - trying optimally by eye-balling to see how the species distributed. Since it was the old tradition that black oak was the one end and sugar maple was the other, so we generally started out like that ... we put the black oak at one end and the sugar maple at the other and saw how the others fell. And then juggled them to optimum - to see whether you could make the smoothest curve. ... Then with all the tree species you got the continuum-type sequence (McIntosh 1978)".

The best way to organise the stands appeared to be into a sequence of continuous variation, each dominant gradually peaking in frequency, and then dropping out, along a continuum between stands dominated, at the one end, by sugar maple Acer saccharum (Marsh) and, at the other, by stands dominated by black oak Quercus velutina (Lam.). There were no distinct "associations" of species. Each species had its optimum occurrence at a different point on the scale.

This idea of a continuum of species distribution was first presented by Curtis and McIntosh at the annual meeting of the Ecological Society in September 1950. Normally one would expect the appearance of a radical revision of the accepted wisdom to stimulate controversy. Oddly enough, the paper attracted very little comment. The manuscript was readily accepted by Ecology and appeared in 1951 (Curtis and McIntosh 1951). Curtis was not, indeed, altogether pleased by the calm reaction to what he regarded as the innovatory work of the Wisconsin school.

There were a number of reasons for the lack of debate. Curtis was a forceful public speaker and a clear writer. His research methods were sophisticated and rigorously quantitative. His papers were carefully prepared and presented. Curtis's students were similarly well disciplined. The Wisconsin School was not an opponent to engage with lightly. Oddly enough, however, one of the most important factors in easing the acceptance of the Wisconsin work seems to have been a widespread confusion as to what the continuum actually referred to.

As we have seen, Curtis's upland forest continuum consisted of a series with black oak communities at one end and sugar maple communities at the other. This was "traditional", as McIntosh put it, because the black oak was regarded as being a pioneer species and the sugar maple as a more mesic, climax species. Thus the two ends of the Wis- consin continuum coincided with points along a perfectly conventional Clementsian successional series. Furthermore, much of the vocabulary with which Curtis and McIntosh described the upland forest continuum was borrowed from the language of monoclimax theory: "The sequence of the species in this pattern is such that pioneer species are at one end and climax species at the other ... The results ... indicate that Acer saccharum is the tree species best equipped to persist in the terminal forests of the area. All other species are less efficient ... their relative degree of "climaxness" may be evaluated by the spatial relations of their optimum development curves ... (Curtis and McIntosh 1951)".

In one schematic description of the continuum, the different species were linked by arrows which lay in the same direction as, under Clementsian theory, progressive successional change was held to occur.

Thus, despite the explicit support voiced by Curtis and McIntosh for the Gleasonian individualistic hypothesis, the 1951 account of the continuum lent itself to the interpretation that what was being characterised was a continuous sere between pioneer and climax vegetation. That seres were at least occasionally continuous was an accepted part of orthodox ecological theory. Thus it was easy for the traditional ecologist to regard Curtis's work as a very elegant quantitative description of an orthodox concept. This seems to have been the basis on which the paper was accepted by D. B. Lawrence for publication in Ecology: "I would suggest that you reconsider the use of term "ecological adaptation number" which seems to me ambiguous and could mean almost anything. Why not call that idea the "sere number" or "succession number"? (Lawrence 1951)".

In response Curtis eventually chose the term "climax adaptation number" to refer to the position of species along the continuum.

Indeed the Wisconsin group themselves appear to have taken some time to become absolutely clear in their own minds about on the status of the continuum concept. In 1949, Curtis himself wrote about the continuum as if it was a description of succession: "We have erected a succession index for the purpose of classifying upland hardwood on a scale varying from pioneer species on one end to climax species on the other (Curtis 1949)".

And similar sentiments were still being voiced six years later. As late as 1956, Curtis represented his account of the upland forest continuum as, at least partly, a description of a dynamic process of succession: "You are right in your assumption that most of the types in the continuum are not permanent but will be followed by others higher on the scale in the absence of disturbance. The terminal forests (climax, if you will) on the other hand tend to chance much more slowly, always in the direction of sugar maple (Curtis 1956)".

However, the mid-fifties saw Curtis and his associates develop the idea that vegetation varied continuously not 
merely along a single gradient but many simultaneously, a process to be characterised by what they called multiple ordination (Bray and Curtis 1957). In this context, Curtis made it unequivocally clear, as perhaps he did not elsewhere, that the vegetational continuum was to be regarded as existing among and between stands of vegetation that were, from any but a geomorphologic perspective, mature and permanent. In describing a continuous variation between dry, mesic and wet prairies, he maintained: "There is no evidence whatever that the wet prairies are capable of becoming mesic prairies through any reaction their members may have on the habitat, nor can the dry prairies so change their environment as to become mesic (Curtis 1955)".

In other words, continuous variation in vegetation was no longer necessarily associated with successional change. The continuum had come to be unequivocally regarded as a distinctively different phenomenon altogether - as a generally valid description of the characteristics of mature vegetation. Thus the full conception of the vegetational continuum emerged only gradually.

Scientific discovery is often, as Brannigan (1985) pointed out, more of a process over time than a unit-event. In his classic text, "The Structure of Scientific Revolutions", Kuhn (1962) describes how the identification of oxygen occurred over a period of years and was a product of the work of several investigators. The conceptual categories of the older, phlogiston gas chemistry changed gradually as new scientific practices and fresh theoretical resources were progressively developed, giving credibility to the concept of a new gas. Thus the recognition of the reality of the vegetational continuum, like the recognition of the reality of oxygen, emerged from a continuing process of cognitive change. It developed with the sustained articulation of a new programme of research. (see Nicolson 1984, for another similar example from the history of ecology).

Curtis presented the concept of the continuum as a vindication of Henry Allen Gleason's dissent from the community-unit theory and a revival of his individualistic hypothesis. He proclaimed himself to be a disciple of Gleason: "Throughout my phytosociological research I have constantly been stimulated by the ideas of $\mathrm{H}$. A. Gleason whom I consider to be the most outstanding plant ecologist of all time. He was so far ahead of his time that we have not yet caught up to him (Curtis 1958a)".

It is interesting, however, that the individualistic hypothesis was altered as it was revived. Curtis re-interpreted and modified Gleason's ideas in the light of the changed intellectual environment of the nineteen-fifties. For instance, the role given to pure chance as an explanation for species distribution was diminished and greater importance was given to precise adaptation between each plant species and its micro-environment. Thus Curtis wrote, in support of Gleason: "I believe the continuum concept to be only a slight modification of the individualistic concept, in that it holds that species assemblages are formed by chance factors but that the innate adaptational behaviours of the available flora will imprint a pattern upon the results (Curtis 1956)".

Like Herbert Mason, Curtis made an explicit parallel between Gleason's individualistic hypothesis and the modes of explanation which had been developed in postwar biosystematics: "This variation commonly shows a continuous progression of changing combinations of both dominant and subordinate series, resulting in a vegetational continuum, rather than a series of separate, discrete and identifiable segments. The situation is comparable to the case in taxonomy when the breeding barriers between the two species break down. The resulting continuous variates may be studied but not classified (Curtis 1952)".

This was not simply a rhetorical connection. We have already noted similar sentiments in the earlier writing of Herbert Mason on the individualistic hypothesis. The leading biosystematists Wendell Camp and Edgar Anderson (Hagen 1984) were frequent visitors to Madison (Cottam 1978). They followed Curtis's work with great interest, as he did theirs. The two developments, both employing new methods in traditional fields, were parallel responses to the changed intellectual climate produced in the botanical sciences with the growth of population genetics and other evolutionary prespectives. Curtis's version of the individualistic hypothesis, which emphasised species adaptation, thus more closely reflected the intellectual content of post-Second World War biology. The continuum, unlike the Clementsian community-unit theory, was compatible, in principle, with the New Darwinian Synthesis.

\section{Conclusion}

By the 1970s, few plant ecologists in the English-speaking world worked routinely with the idea that vegetation existed in distinct and definite natural kinds. The classification of vegetation into units was now regarded as a matter of convenience rather than a reflection of an underlying unitary reality. Curtis and his colleagues had helped produce a very major shift in ecological theory and practice (McIntosh 1993).

Curtis had come into ecology with an explicit intention to reform the discipline. As a well-trained and accomplished physiologist he knew what were the accepted criteria of the best biological science. These were the standards, methodological and theoretical, that he sought to instil, first into his own students then into plant ecology as a whole. The thrust of his work was to make plant ecology more like mainstream biology, which is to say more quantitative and more Darwinian, than it had previously been.

Acknowledgements - This work was supported by the Wellcome Trust. 


\section{References}

Abir-Am, P. 1982. The discourse of physical power and biological knowledge in the 1930s: a reappraisal of the Rockfeller Foundation's policy in molecular biology. - Soc. Stud. Sci. 12: 341-382.

Anon. 1951. Abstracts of papers given at the Minneapolis meeting. - Bull. Ecol. Soc. Am. 32: 56-57.

Beadle, G. W. 1967. The role of foundations in the development of modern biology. - In: Weaver, W. E. (ed.), United States philanthropic foundations: their history, structure, management and record. Harper Row, pp. 225-240.

Brannigan, A. 1985. The social basis of scientific discoveries. Cambridge Univ. Press.

Bray, J. R. and Curtis, J. T. 1957. An ordination of the upland forest communities of southern Wisconsin. - Ecol. Monogr. 27: 325-349.

Cain, S. 1947. Characteristics of natural areas and factors in their development. - Ecol. Monogr. 17: 187-200.

Clements, F. E. 1916. Plant succession: an analysis of the development of vegetation. - Carnegie Inst.

Cottam, G. 1978. Interview with M. Nicolson, 6 Dec. - Madison, Wisconsin.

Cottam, G. and Curtis, J. T. 1948. The use of the punched card method in phytosociological research. - Ecology 29: 516 519.

Cottam, G. and Curtis, J. T. 1949. A method for making rapid surveys of woodlands by means of pairs of randomly selected trees. - Ecology 30: 101-104.

Curtis, J. T. 1946. Letter to W. S. Cooper, 12 March. - Curtis Papers, Univ. Archives, Wisconsin, Madison.

Curtis, J. T. 1947. The Palo Verde forest type near Gonaives, Haiti and its relation to the surrounding vegetation. - Carib. For. 8: 1-12.

Curtis, J. T. 1949. Letter to W. H. Camp, 6 July. - Curtis Papers, Univ. Archives, Wisconsin, Madison.

Curtis J. T. 1952. The continuum in relation to the classification of plant communities. - Presented to A.A.A.S. symposium, unpublished typescript in the Curtis Papers.

Curtis, J. T. 1955. A prairie continuum in Wisconsin. - Ecology 36: 558-565.

Curtis, J. T. 1956. Letter to C. G. van Steenis, 8 Oct. - Curtis Papers, Univ. Archives, Wisconsin, Madison.

Curtis, J. T. 1958a. Letter to W.E. Martin, 8 Jan. - Curtis Papers, Univ. Archives, Wisconsin, Madison.

Curtis, J. T. 1958b. Letter to P. Grieg-Smith, 10 Feb. - Curtis Papers, Univ. Archives, Wisconsin, Madison.

Curtis, J. T. 1959a. The vegetation of Wisconsin. - Wisconsin Univ. Press.

Curtis, J. T. 1959b. Letter to H. J. Oosting, 6 Aug. - Curtis Papers, Univ. Archives, Wisconsin, Madison.

Curtis, J. T. and Juday, C. 1937. Photosynthesis of algae in Wisconsin lakes III: observations of 1935. - Int. Rev. Hydrobiol. 35: 122-133.

Curtis, J. T. and McIntosh, R. P. 1951. An upland forest continuum in the prairie-forest border region of Wisconsin. - Ecology 32: 476-496.

Egler, F. E. 1947. Arid southeast Oahu vegetation, Hawaii. Ecol. Monogr. 17: 384-435.

Geison, G. L. and Holmes, F. L. 1993. Research schools: historical reappraisals. - Univ. of Pennsylvania, Dept of History and Sociology of Science.
Gleason, H. A. 1926. The individualistic concept of the plant association. - Bull. Torrey Bot. Club 53: 7-26.

Hagen, J. B. 1984. Experimentalists and naturalists in twentiethcentury botany: experimental taxonomy, 1920-1950. - J. Hist. Biol. 17: 249-270.

Hagen, J. B. 1992. An entangled bank: the origins of ecosystem ecology. - Rutgers Univ. Press.

Kuhn, T. S. 1962. The structure of scientific revolutions. - Chicago Univ. Press.

Lawrence, D. B. 1948. Letter to J. T. Curtis, 3 August. - Curtis Papers, Univ. Archives, Wisconsin, Madison.

Lawrence, D. B. 1951. Letter to J. T. Curtis, 25 March. - Curtis Papers, Univ. Archives, Wisconsin, Madison.

Mason, H. 1947. Evolution of certain floristic associations in western North America. - Ecol. Monogr. 17: 203-210.

McIntosh, R. P. 1975. Henry Allan Gleason - individualistic ecologist 1882-1975: his contributions to ecological theory. - Bull. Torrey Bot. Club 102: 253-273.

McIntosh, R. P. 1978. Interview with M. Nicolson, 8 Dec. Univ. of Notre Dame.

McIntosh, R. P. 1983. Pioneer support for ecology. - Bioscience 33: 107-112.

McIntosh, R. P. 1993. The continuum continued: John T. Curtis's influence on ecology. - In: Fralish, J. S., Loucks, O. C. and McIntosh, R. P. (eds), Fifty years of Wisconsin plant ecology. Wisconsin Acad. Sci.

Morrell, J. B. 1972. The chemist breeders: the research schools of Leibig and Thomas Thomson. - Ambix 19: 1-46.

Nichols, G. 1923. A working basis for the ecological classification of plant communities. - Ecology 4: 11-23, 154-179.

Nicolson, M. 1984. The development of plant ecology. - Ph.D. thesis, Edinburgh Univ.

Nicolson, M. 1989. National styles, divergent classifications: a comparative case study from the history of French and American plant ecology. - Knowledge and Society 8: 139186.

Nicolson, M. 1990. Henry Allan Gleason and the individualistic hypothesis of the plant community: the structure of a botanist's career. - Bot. Rev. 56: 91-161.

Odum, E. P. 1977. The emergence of ecology as a new integrative discipline. - Science 195: 1289-1293.

Provine, W. B. 1978. The role of mathematical population geneticists in the evolutionary synthesis of the 1930s and 1940s. Stud. Hist. Biol. 2: 167-192.

Tobey, R. 1981. Saving the prairies: the life cycle of the founding school of American plant ecology. - California Univ. Press.

Walker, J. C. 1958. Benjamin Minge Duggar. - Biog. Memoirs Nat. Acad. Sci. 32: 113-131.

Whittaker, R. H. 1951. A criticism of the plant association and climatic climax concepts. - Northwest Sci. 25: 17-31.

Whittaker, R. H. 1953. A consideration of climax theory: the climax as population and pattern. - Ecol. Monogr. 23: 4178.

Whittaker, R. H. 1962. Classification of natural communities. Bot. Gaz. 28: 1-239.

Whittaker, R. H. 1975. Ordination and classification of communities. - Nijhoff/Junk, Holland.

Young, V. A. 1954. The Frederic E. Clements memorial. - Ecology 35: 116 . 